\title{
Motor Neurons Tune Premotor Activity in a Vertebrate Central Pattern Generator
}

\author{
[-Kristy J. Lawton, ${ }^{1}$-Wick M. Perry, ${ }^{1}{ }^{-}$Ayako Yamaguchi, ${ }^{2}$ and ${ }^{\circ}$ Erik Zornik $^{1}$ \\ ${ }^{1}$ Biology Department, Reed College, Portland, Oregon 97202, and ²Biology Department, University of Utah, Salt Lake City, Utah 84112
}

Central patterns generators (CPGs) are neural circuits that drive rhythmic motor output without sensory feedback. Vertebrate CPGs are generally believed to operate in a top-down manner in which premotor interneurons activate motor neurons that in turn drive muscles. In contrast, the frog (Xenopus laevis) vocal CPG contains a functionally unexplored neuronal projection from the motor nucleus to the premotor nucleus, indicating a recurrent pathway that may contribute to rhythm generation. In this study, we characterized the function of this bottom-up connection. The X. laevis vocal CPG produces a $50-60 \mathrm{~Hz}$ "fast trill" song used by males during courtship. We recorded "fictive vocalizations" in the in vitro CPG from the laryngeal nerve while simultaneously recording premotor activity at the population and single-cell level. We show that transecting the motor-to-premotor projection eliminated the characteristic firing rate of premotor neurons. Silencing motor neurons with the intracellular sodium channel blocker QX-314 also disrupted premotor rhythms, as did blockade of nicotinic synapses in the motor nucleus (the putative location of motor neuron-to-interneuron connections). Electrically stimulating the laryngeal nerve elicited primarily IPSPs in premotor neurons that could be blocked by a nicotinic receptor antagonist. Our results indicate that an inhibitory signal, activated by motor neurons, is required for proper CPG function. To our knowledge, these findings represent the first example of a CPG in which precise premotor rhythms are tuned by motor neuron activity.

Key words: CPG; feedback; synchrony; vocal; vocalization; Xenopus

\section{Significance Statement}

Central pattern generators (CPGs) are neural circuits that produce rhythmic behaviors. In vertebrates, motor neurons are not commonly known to contribute to CPG function, with the exception of a few spinal circuits where the functional significance of motor neuron feedback is still poorly understood. The frog hindbrain vocal circuit contains a previously unexplored connection from the motor to premotor region. Our results indicate that motor neurons activate this bottom-up connection, and blocking this signal eliminates normal premotor activity. These findings may promote increased awareness of potential involvement of motor neurons in a wider range of CPGs, perhaps clarifying our understanding of network principles underlying motor behaviors in numerous organisms, including humans.

\section{Introduction}

Central pattern generators (CPGs) are neural networks that produce rhythmic behaviors, such as respiration and courtship song. CPGs produce rhythmic output even when isolated from descending inputs or sensory feedback (Marder and Bucher, 2001; Grillner, 2006). In several invertebrate CPGs, motor neurons are an integral part of the circuit, with extensive functional connec-

\footnotetext{
Received Aug. 31, 2016; revised Feb. 5, 2017; accepted Feb. 13, 2017.

Author contributions: K.J.L., W.M.P., A.Y., and E.Z. designed research; K.J.L., W.M.P., and E.Z. performed research; K.J.L. and W.M.P. analyzed data; K.J.L. and E.Z. wrote the paper.

This work was supported by National Institutes of Health Grant NS091977 and Reed College startup funds. We thank Charlotte Barkan and two anonymous reviewers for helpful feedback on the manuscript.

The authors declare no competing financial interests.

Correspondence should be addressed to Dr. Erik Zornik, 3203 SE Woodstock Blvd, Portland, OR 97202. E-mail: ezornik@reed.edu.

DOI:10.1523/JNEUROSCI.2755-16.2017

Copyright $\odot 2017$ the authors $\quad 0270-6474 / 17 / 373264-12 \$ 15.00 / 0$
}

tions with premotor neurons (Arshavsky et al., 1997; Marder and Bucher, 2007; García-Crescioni and Miller, 2011). In the majority of vertebrate CPGs, motor neurons are thought to be passive output cells (Kiehn, 2006, 2011; Guertin and Steuer, 2009), although growing evidence from spinal circuits is challenging this assumption.

In chick and rodent spinal CPGs, motor neurons are known to send excitatory projections to Renshaw cells that in turn influence the activity of motor neurons and other Renshaw cells (Wenner and O'Donovan, 1999; Kiehn and Butt, 2003; Nishimaru et al., 2005, 2006). In the Xenopus tadpole swimming CPG, motor neurons synapse onto each other and onto interneurons in the same circuit, and may contribute to rhythm generation (Perrins and Roberts, 1995a; Roberts et al., 2012, 2014). Studies in both chick embryo (Wenner and O'Donovan, 1999, 2001) and embryonic and neonatal rodent spinal cord (Hanson and Landmesser, 2003; Mentis et al., 2005; Machacek and Hochman, 2006; Bonnot et al., 2009) have found 
electrophysiological and anatomical evidence that motor neurons can activate premotor pathways in the locomotor CPG. In zebrafish, recent work also showed that motor neurons may influence premotor neuron activity via electrical synapses (Song et al., 2016). Thus, there is preliminary evidence indicating that motor neurons can contribute to locomotor rhythm generation. To our knowledge, however, no previous studies have identified motor neuron involvement in nonspinal vertebrate CPGs.

The vocal system of the frog Xenopus laevis provides a powerful framework for identifying mechanisms of CPG function in the vertebrate hindbrain (Zornik and Kelley, 2011). The vocal CPG can be activated in vitro, enabling the recording of "fictive vocalizations" from the laryngeal nerve along with intracellular and extracellular recordings of premotor activity. A prominent component of the male courtship call, fast trill, consists of repeating trains of 50-60 Hz sound pulses (Wetzel and Kelley, 1983). Premotor neurons, termed "fast trill neurons" (FTNs), have been identified that appear to generate the fast trill rhythm (Zornik and Yamaguchi, 2012).

The X. laevis vocal CPG consists of two hindbrain nuclei: the premotor nucleus DTAM (used as a proper noun) in the pons, and the laryngeal motor nucleus (n.) IX-X in the caudal hindbrain (Rhodes et al., 2007). Anatomical evidence has indicated that premotor neurons in DTAM project to n.IX-X (Wetzel et al., 1985; Zornik and Kelley, 2007), and electrophysiological experiments have shown that they can directly activate vocal motor neurons (Zornik and Kelley, 2008). The circuit also possesses a prominent ascending projection from n.IX-X to DTAM (Fig. 1) (Zornik and Kelley, 2007), but its functional role has not been previously investigated.

The goal of this study was to examine the role of this feedback projection. Because of mounting evidence of motor neuron involvement in spinal circuits, we hypothesized that motor neurons may also contribute to the function of CPGs located in the brain. We used a combination of physical transections, pharmacological perturbations, whole-cell patch-clamp recordings, and nerve stimulations in the fictively vocalizing isolated brain preparation to test the hypothesis that the motor-to-premotor projection is activated by vocal motor neurons and that it is required for generating normal premotor vocal rhythms. Our results support the hypothesis that motor neurons tune vocal patterns by activating ascending interneurons.

\section{Materials and Methods}

Animals. Adult male wild-type X. laevis frogs (Nasco) (weight, $43.3 \pm$ $7.3 \mathrm{~g}$; length, $7.1 \pm 0.5 \mathrm{~cm}$ ) were group-housed (up to 15 per tank) in recirculating water in PETG aquaria (Aquaneering) and maintained on a 12:12 h light/dark cycle. Protocols were approved by the Reed College Institutional Animal Care and Use Committee.

In vitro brain preparation. To isolate brains for fictive vocal recordings, animals were anesthetized with subcutaneous injections of $0.5-0.7 \mathrm{ml}$ of $1.3 \%$ tricaine methanesulfonate (Sigma), placed on ice for at least $5 \mathrm{~min}$, and decapitated. Brains were extracted in a dish containing $\sim 10^{\circ} \mathrm{C}$ saline (in mM as follows: $96 \mathrm{NaCl}, 20 \mathrm{NaHCO}_{3}, 11$ glucose, $10 \mathrm{HEPES}, 2 \mathrm{CaCl}_{2}$, $2 \mathrm{KCl}$, and $0.5 \mathrm{MgCl}_{2}, \mathrm{pH} 7.8$ ), which was continuously oxygenated with $99 \% \mathrm{O}_{2} / 1 \% \mathrm{CO}_{2}$. Isolated brains were pinned in a Petri dish lined with silicone elastomer (Sylgard; Dow Corning) containing oxygenated saline. The roots of cranial nerve N.IX-X were cut, except for the most caudal root containing all laryngeal motor neuron axons (Simpson et al., 1986) (referred to here as the laryngeal nerve). A dorsal midline cut was made through the center of the cerebellum and optic tectum between the third and fourth ventricles, dorsal to the ventricle floor. This region was then pinned laterally to allow access to the vocal premotor nucleus, DTAM, as previously described (Zornik and Yamaguchi, 2012). After $1 \mathrm{~h}$, brains were transferred to a Sylgard-lined Petri recording dish continuously

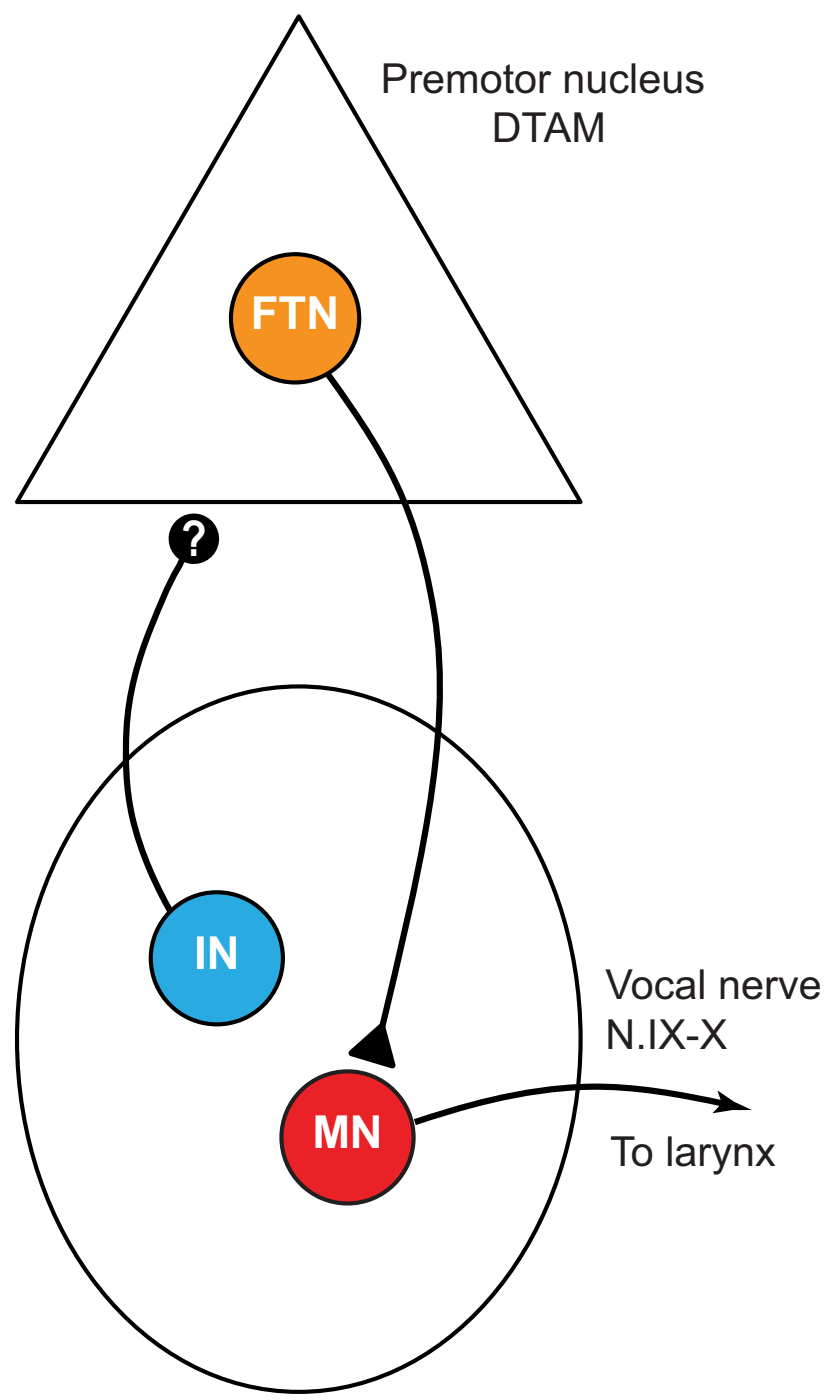

Vocal motor nucleus n.IX-X

Figure 1. The $X$. laevis adult vocal CPG provides a system for detailed study of a rhythmic motor circuit. Premotor FTNs in DTAM project to vocal motor neurons (MN) in the laryngeal motor nucleus (n.IX-X), which activate laryngeal muscles to produce vocalizations. An interneuron (IN) population projects from motor to premotor nuclei via an uncharacterized synapse (indicated by "?").

perfused with $\sim 22^{\circ} \mathrm{C}$ oxygenated saline. In some experiments, transverse transections were made just caudal to N.VIII, thus severing the connections between $\mathrm{n}$.IX-X and DTAM.

Electrophysiology. Serotonin (5-HT) bath-applied to isolated brains induces trains of compound action potentials (CAPs) in the laryngeal nerve. These CAP trains represent "fictive" vocalization, as they closely match the activity recorded during calling in intact frogs (Yamaguchi and Kelley, 2000; Rhodes et al., 2007). We measured fictive vocalizations by placing a suction electrode over the cut end of N.IX-X (Fig. 2A). In nerve silencing experiments (described below), cut nerve endings were placed in Vaseline wells; to perform differential recordings in this configuration, one silver wire electrode was placed inside the well and the other silver wire electrode was placed just outside the well. Simultaneous local field potential (LFP) recordings were obtained via a $0.5 \mathrm{M} \Omega$ tungsten electrode (Microprobes) inserted into DTAM.

Nerve recordings and DTAM LFP signals were amplified $1000 \times$ (differential amplifier models 1700 and 1800, respectively; A-M Systems) and bandpass filtered $(10 \mathrm{~Hz}$ to $5 \mathrm{kHz}$ and $0.1-5 \mathrm{kHz}$, respectively). All signals were digitized at $10 \mathrm{kHz}$ and recorded with Clampex software (Molecular Devices). 
A

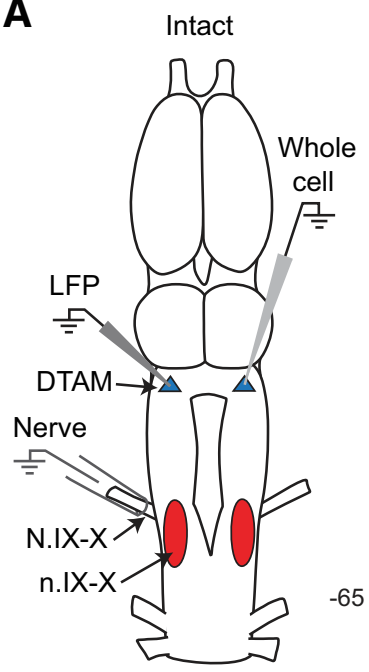

C

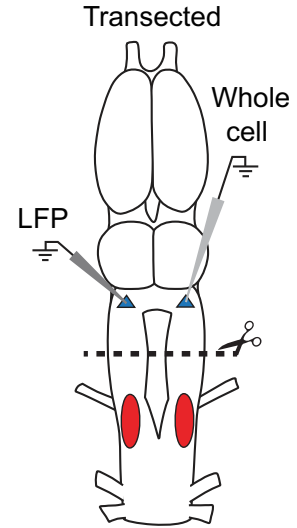

E

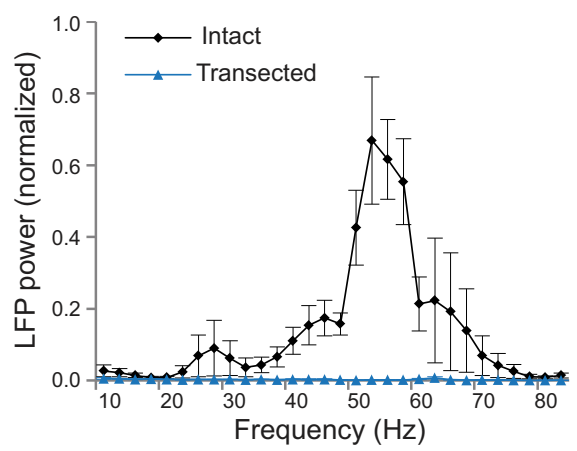

B
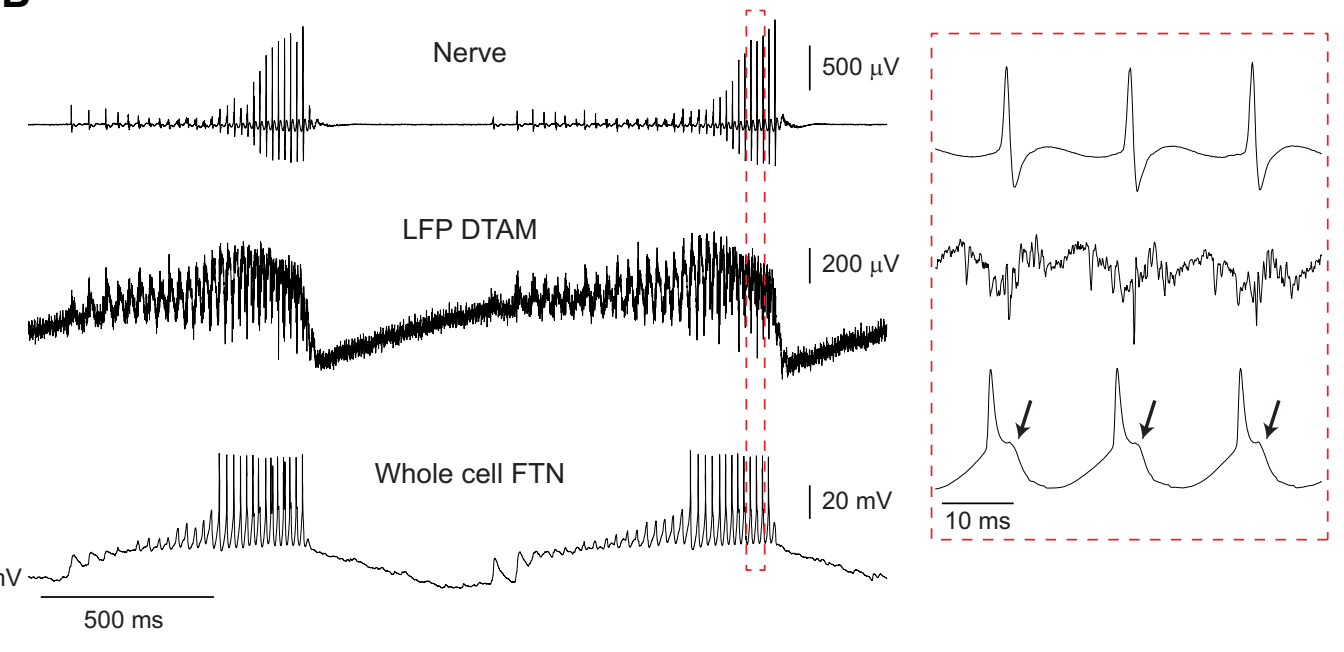

D

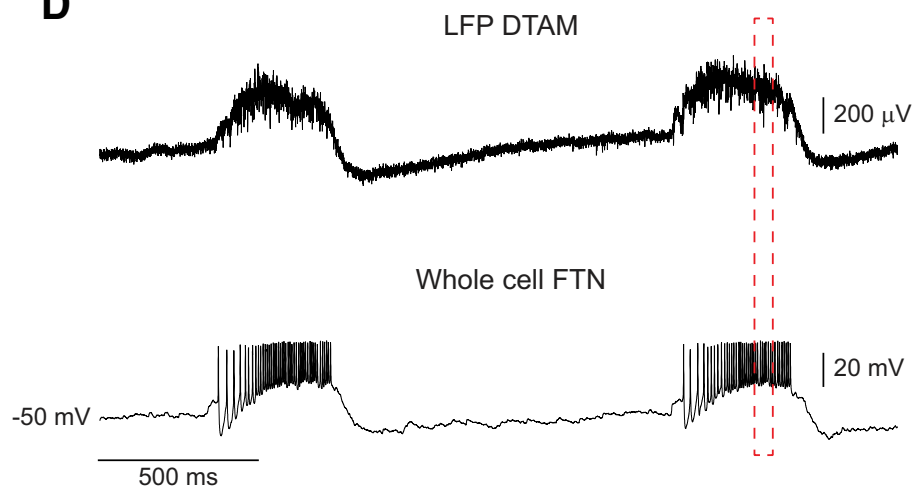

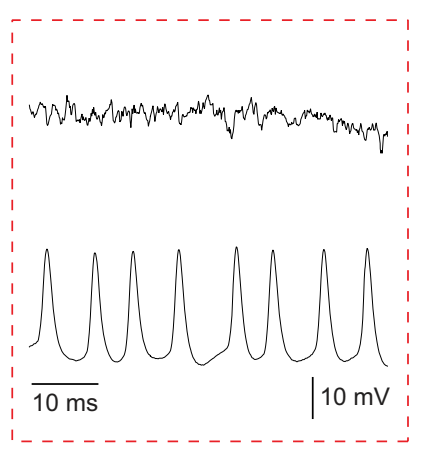

F

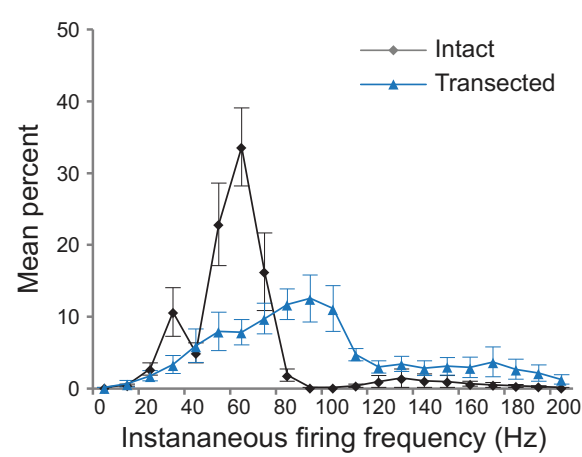

G

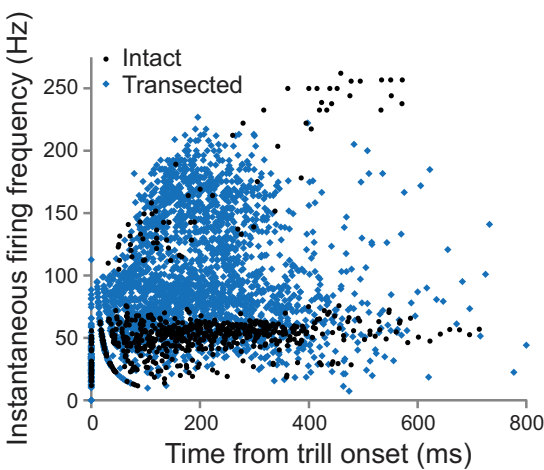

Figure 2. Normal premotor rhythms require motor nucleus input. $A$, Dorsal view of the intact adult $X$. laevis brain showing the vocal motor nucleus (n.IX-X; red oval) and premotor region (DTAM; blue triangle). Suction electrodes record fictive vocalization from the laryngeal nerve (N.IX-X). Premotor neurons in DTAM are recorded at the population level with an LFP electrode, and individually via a patch-clamp electrode. B, 5-HT-induced fictive vocalizations in the intact brain: the laryngeal nerve (top) produces "fast trills" consisting of 50 - $60 \mathrm{~Hz}$ trains of CAPs. Nerve CAPs coincide with activity in DTAM LFP (middle) and patch-clamp (bottom) recordings. Red box represents area of expanded traces; note the presence of IPSPs following each spike (arrows). $C$, To identify the role of the motor nucleus in tuning premotor rhythms, we transected the brain between n.IX-X and DTAM (dotted line) before recording premotor neuron activity. $\mathrm{D}$, After transection, 5 -HT continued to induce premotor activity in DTAM: LFP waves (top trace) persist in transected brains; however, these lack the normal $50-60 \mathrm{~Hz}$ phasic activity seen in intact brains. Whole-cell recordings of premotor FTNs (bottom) continue to exhibit long-lasting depolarizations during LFP waves but show altered spike patterns. Red box represents area of expanded traces. $\boldsymbol{E}$, Power spectra of LFP (2.5 Hz bins): intact premotor $50-60 \mathrm{~Hz}$ rhythms are lost following transection ( $n=5$ brains). Values are mean \pm SEM. $F$, Mean FTN spike frequency distributions for all intact and transected FTNs $(n=6$ and $n=9$ cells, respectively, from separate brains). FTN spike rates on average are faster in transected brains. Values are mean \pm SEM. G, Scatterplot of instantaneous FTN spike rates during fast trills (intact) or LFP waves (transected). In intact brains, FTNs tend to spike primarily at fast trill rates; in transected brains, FTN spike rates are faster and more variable. Time 0 indicates the time of the first spike in each burst.

Whole-cell recordings were obtained in DTAM at depths of 79-207 $\mu \mathrm{m}$ below the ventricular surface, as previously described (Zornik and Yamaguchi, 2012). Patch-clamp electrodes $(6-10 \mathrm{M} \Omega$ ) were made from thick-walled borosilicate capillary tubes $(1.5 \mathrm{~mm}$ outer diameter; 0.86 mm inner diameter), pulled on a Flaming/Brown style microelectrode puller (P-1000; Sutter Instruments). A blind search strategy was used to locate premotor neurons in DTAM: positive pressure was applied to the electrode before advancing vertically into DTAM using a motorized 
micromanipulator (MC1000e; Siskiyou). Cell searches began after the electrode reached a depth of $50 \mu \mathrm{m}$, after which the electrode was slowly advanced through the tissue until encountering a rapid and reliable increase in resistance, indicating proximity to a cell. Positive pressure was then released, a gigaohm $(\mathrm{G} \Omega)$ seal obtained, and brief negative suction applied to achieve whole-cell access. Whole-cell recordings were determined to be premotor neurons based on their synchronized activity with 5-HT-induced fictive fast trills or LFP waves.

For nerve stimulations, brief $(100 \mu \mathrm{s})$ isolated current pulses were generated through the suction electrode on the laryngeal nerve (model 3800 stimulator, A-M Systems). Currents were increased until a postsynaptic potential (PSP) was observed in the whole-cell recording. Effective current intensities ranged from $200 \mu \mathrm{A}$ to $2 \mathrm{~mA}$. Stimulation trials consisted of 10 single pulses given every $10 \mathrm{~s}$. During pharmacological experiments, trials were repeated every $10 \mathrm{~min}$.

Pharmacological manipulations. For eliciting fictive song in all experiments, saline superfusion was paused and $500 \mu$ l of 5-HT solution was added to the recording bath ( $60 \mu \mathrm{M}$ final concentration). After 3-4 min of recording, superfusion was resumed $(>200 \mathrm{ml} / \mathrm{h}$ ) for $1 \mathrm{~h}$ to wash out the serotonin.

To inactivate motor neurons, the intracellular $\mathrm{Na}^{+}$channel blocker QX-314 (200 mm, Sigma) was added to Vaseline wells formed around the cut ends of N.IX-X before recording premotor whole-cell and LFP activity. QX-314 was applied to the wells immediately following control 5-HT-induced fictive vocalizations, and allowed to diffuse into nerve axons during the $1 \mathrm{~h}$ wash period.

During some stimulation experiments (described above), the nAChR blocker tubocurarine $(25 \mu \mathrm{M}$, Tocris Bioscience) was bath applied while recording from individual premotor neurons. After obtaining stimulationinduced PSPs, tubocurarine was bath-applied and additional stimulations were made $10 \mathrm{~min}$ later; superfusion was then reinstated for the $1 \mathrm{~h}$ drug washout while stimulations were continually repeated every $10 \mathrm{~min}$.

To locally block cholinergic synapses in the motor nucleus, we injected tubocurarine into n.IX-X via pressure injection (Picospritzer III; Parker Hannifin). Tubocurarine mixed with in $7.5 \%$ tetramethyrhodamine dextran (3000 MW; Thermo Fisher Scientific) was loaded into a thickwalled borosilicate capillary tube ( $1.5 \mathrm{~mm}$ outer diameter; $0.86 \mathrm{~mm}$ inner diameter) pulled (P1000, Sutter Instruments) and broken to a tip diameter of $20-30 \mu \mathrm{m}$. The pipette was lowered into n.IX-X using a motorized micromanipulator (MC1000e; Siskiyou) to a depth of $800-900 \mu \mathrm{m}$ below the dorsal surface. A series of $20 \mathrm{~ms}$ duration pressure pulses at $20 \mathrm{psi}$ were applied; all brains received between 100 and 200 pulses until substantial dye was observed in the area. High doses ( 5 or $25 \mathrm{~mm}$, final concentration) were used to compensate for dilution of the small injection volumes. Control experiments were identical, except that physiological saline replaced tubocurarine in the dye mixture. Only experiments where brains produced at least 5 trills after a $1-2 \mathrm{~h}$ washout were included in the dataset.

Histology. Injection sites in anteromedial n.IX-X were confirmed via cryosectioning at $30 \mu \mathrm{m}$ on a Leica cryostat and visualized on an upright wide-field fluorescence microscope (Olympus, model BX60). Sectioning and imaging analysis were performed blind to experimental group.

Data analysis. Clampfit software (Molecular Devices) threshold search was used to quantify instantaneous spike rate for 10 spike bursts per premotor neuron. Instantaneous spike frequencies were calculated as the reciprocal of each spike interval; histograms were generated by calculating the percentage of instantaneous spike frequencies at each frequency range (bins $=5 \mathrm{~Hz}$ for quantification, $10 \mathrm{~Hz}$ for graphical representations).

Clampfit threshold search was used to quantify CAP amplitude of nerve recordings for tubocurarine ( $5 \mathrm{~mm}$ ) injection experiments. The last 10 CAPs in each trill were measured, using 5-10 trills per experiment.

Normal premotor vocal LFP recordings consist of slow waves containing phasic activity at fast trill rates $(50-60 \mathrm{~Hz})$. LFP waves persist after transection, although phasic activity is lost (Zornik et al., 2010). To quantify premotor neuron population activity, power spectra of LFP waves were compared in intact and experimental brains. Power spectra were calculated from the last $500 \mathrm{~ms}$ of each wave for 5 consecutive waves in each brain. In experiments where we also measured motor neuron population activity, power spectrum analysis was performed on nerve activ- ity occurring during the LFP waves. The power spectra were generated in Clampfit and normalized to the peak of their respective pretreatment controls. Power data for frequencies $<10 \mathrm{~Hz}$ were excluded.

For nerve stimulation-induced PSPs, traces from at least 5 stimulations were averaged; peak onset latency was measured as the time of $10 \%$ maximum peak amplitude. The PSP amplitude was calculated from the averaged trace as the maximum voltage change relative to the prestimulation resting potential.

Statistics. All statistical tests were performed in Prism 7. The MannWhitney $U$ test was used for experiments with two independent groups: comparison of the intact versus transected premotor neuron peak firing frequency, comparison of the change in peak frequency for the saline and $5 \mathrm{~mm}$ tubocurarine injections, and comparison of the contralateral versus ipsilateral side for premotor neuron PSP amplitude and latency (relative to the stimulated nerve). No statistical tests were performed on the QX314 FTN data due to small sample size $(n=3)$. The $25 \mathrm{~mm}$ tubocurarine injections were omitted from the change in peak frequency analysis due to the lack of a measurable peak. To assess the relative nerve or LFP power at control peak frequencies following pressure injections (saline, $5 \mathrm{~mm}$ tubo, and $25 \mathrm{~mm}$ tubo), we used the Kruskal-Wallis test (for three independent groups) with Dunn's post hoc test with correction for multiple comparisons. To assess the effect of tubocurarine on PSP amplitude in premotor neurons during nerve stimulations, we used the Friedman test for repeated measures with Dunn's post hoc test with correction for multiple comparisons. Data are reported as mean \pm SEM.

\section{Results}

Normal premotor activity requires motor nucleus feedback

The male advertisement call is a temporally precise series of sound pulses produced at stereotyped rates, resulting from contraction of a single set of laryngeal muscles (Tobias and Kelley, 1987; Yager, 1992). Each sound pulse is generated by synchronous firing of a pool of motor neurons, which produce CAPs in the laryngeal nerve (caudal root of N.IX-X) that lead to activation of the laryngeal muscles (Yamaguchi and Kelley, 2000). In response to 5-HT application to the intact in vitro brain (Fig. $2 \mathrm{~A}$ ), the predominant fictive vocalization recorded from N.IX-X begins with a relatively slow and variable CAP repetition rate $(20-40 \mathrm{~Hz})$ followed by a fast trill, a $50-60 \mathrm{~Hz}$ train of CAPs (Fig. $2 B$, top). This pattern of nerve activity is similar to the CAP trains recorded from the laryngeal nerve of males calling in vivo (Yamaguchi and Kelley, 2000). LFP recordings in DTAM reveal phasic bursts that correspond to each nerve CAP. Throughout fictive calling, there is a slow LFP wave that coincides with the onset and offset of each fast trill (Zornik et al., 2010) (Fig. 2B, middle).

We wished to identify the functional significance of neuronal projections from the vocal motor nucleus (n.IX-X) to the premotor nucleus, DTAM (Fig. 1). To do so, we recorded population-level LFP and single-cell level (patch-clamp recordings) premotor activity in DTAM before and after physically transecting between the motor and premotor nuclei (Fig. 2). It was previously shown that 5-HTinduced fictive vocalizations in the laryngeal nerve are eliminated following transections between DTAM and n.IX-X (Rhodes et al., 2007). 5-HT application continues to induce DTAM LFP waves in transected brains, but phasic $50-60 \mathrm{~Hz}$ activity is lost (Zornik et al., 2010) (Fig. 2D, top). Power spectra of LFP activity between 10 and 85 $\mathrm{Hz}$ clearly demonstrate the dramatic effect of transection; LFP recordings in intact brains show a strong peak between 50 and $60 \mathrm{~Hz}$, but this frequency band is completely eliminated following transection (Fig. $2 E ; n=5$ brains). These results suggest that synchronous premotor activity is eliminated by disrupting the motor-to-premotor projection.

Individual neurons in the premotor nucleus DTAM show similar activity patterns to LFP activity (Zornik and Yamaguchi, 2012). FTNs produce a long-lasting depolarization throughout 
each fictive fast trill and LFP wave and generate spikes phaselocked to each CAP (Fig. 2B, bottom), with each spike followed by an IPSP (Fig. $2 B$, inset, bottom, arrows). In transected brains, FTNs continue to generate long-lasting depolarizations in response to 5-HT application. These depolarizations occur during each LFP wave, as in the intact brain; however, the FTN spikes are no longer generated at primarily fast trill frequencies during these depolarizations (Fig. 2D, bottom).

To quantify the differences in FTN firing patterns, we generated histograms of instantaneous spike frequencies (bin width: 5 $\mathrm{Hz}$ ) and scatterplots of spike frequencies over trill duration. In intact brains, instantaneous firing rates are clustered around a clear peak in the range associated with fictive fast trills. Peak spike rates for individual FTNs ranged between 50 and $65 \mathrm{~Hz}(55.8 \pm$ $2.2 \mathrm{~Hz}$; Fig. $2 F ; n=6$ cells in 6 brains). A smaller peak at $\sim 30 \mathrm{~Hz}$ is also prominent due to occasional spike failures during the $\sim 60$ $\mathrm{Hz}$ fast trill. In the intact brain, the majority of FTN spikes occur at fast trill rates $(50-60 \mathrm{~Hz}$; Fig. $2 G)$. Scatterplots of individual FTNs reveal that most cells increase their spike rate at the beginning of each trill before attaining characteristic fast trill rates (Fig. $3 A-C)$. In some cells, higher frequency spike rates occur due to the presence of doublet and triplet spikes associated with each nerve CAP (Fig. 3C) (Zornik and Yamaguchi, 2012).

In contrast, FTN spike rates in transected brains tended to be more variable both within and between neurons compared with recordings in intact brains. Frequency peaks ranged from 45 to $170 \mathrm{~Hz}$. Overall, the average FTN peak spike frequency was significantly faster compared with intact brains (Fig. $2 F$; peak $=$ $96.7 \pm 13.5 \mathrm{~Hz} ; n=9$ cells in 9 brains; $U=6.5, p=0.0132$ ). Spikes were not only faster but also occurred at a broader range of rates in transected brains (Fig. 2G). Some individual neurons fired within a relatively narrow frequency band, albeit at higher than normal rates (Fig. 3D). Most neurons, however, exhibited a broader firing rate distribution, typically much faster than controls (Fig. 3E,F). Scatterplots show that in transected brains, FTN spike rates often increase throughout each burst, attaining faster and broader ranges of spike rates than controls (Fig. $3 E, F$ ). These findings, together with the results of our population-level analyses, suggest that the motor-to-premotor projection is essential for tuning the premotor fast trill rhythm.

\section{Effect of silencing motor neurons}

We wished to test whether motor neurons themselves might be responsible for activating the motor-to-premotor projection. To test whether n.IX-X feedback to DTAM depends on motor neuron activity, we silenced vocal motor neurons in the intact brain by backfilling the laryngeal nerve with the intracellular sodium channel blocker QX-314 (Fig. 4A). LFP and whole-cell recordings during these experiments were similar to those observed in transection experiments (Fig. 4B). Slow LFP waves in DTAM were still induced by 5 -HT application, but the $50-60 \mathrm{~Hz}$ phasic patterns were absent, as evidenced by the dramatic loss of power in that frequency range (Fig. $4 C ; n=5$ brains). Corresponding FTN activity was also faster and more variable than controls, with peak rates ranging between 70 and $90 \mathrm{~Hz}$ (Fig. $4 D ; n=3$ cells in 3 brains; no statistical test was performed due to the small sample size). These results indicate that (1) transection results can be explained by the loss of inputs from motor neurons and (2) motor neurons activate the motor-to-premotor feedback signal necessary for appropriate premotor tuning.

\section{Blocking cholinergic signaling in n.IX-X disrupts premotor activity}

Previous anatomical experiments revealed a motor-to-premotor projection that arises from a population of interneurons in anteromedial n.IX-X that project to DTAM (Zornik and Kelley, 2007). We hypothesized that motor neurons may act on the premotor circuit by exciting these intervening interneurons in n.IX-X. To test this, we used the nAChR blocker tubocurarine, which reversibly antagonizes nAChRs and therefore blocks synaptic transmission of motor neurons (Usiak and Landmesser, 1999). To avoid affecting other brain regions, we locally applied tubocurarine (or a saline control) into anteromedial n.IX-X via pressure injection (Fig. 5A). In control experiments, brains produced largely normal fictive vocalizations following saline injection, whereas low-dose (5 mM) and high-dose $(25 \mathrm{~mm})$ tubocurarine injections produced significant or complete disruption of CPG function, respectively (Fig. $5 B$ ). In 4 of 9 brains with low-dose injections, fictive fast trills were blocked, although most of these ( 3 of 4 brains) did produce slow CAP trains without LFP waves. In the other 5 cases, fictive fast trills were still produced (Fig. $5 B$ ), although CAP amplitude was reduced to $43 \pm 4 \%$ of the preinjection control. In contrast, no fictive calling was produced following high-dose injections, although LFP waves (as seen in transected and motor neuron-silenced brains) were still induced by 5 -HT.

Unlike motor neuron silencing by QX-314, the laryngeal nerve was still active following tubocurarine injection experiments. Therefore, we were able to determine the effect of each treatment on nerve power spectra following drug injection and 5-HT application. Following saline control experiments, there was no clear change in the most prominent frequencies recorded in the nerve relative to preinjection controls (Fig. $5 C ; n=6$ brains). In response to $5 \mathrm{~mm}$ tubocurarine, there was a slight leftward shift in the most prevalent frequencies (Fig. $5 D ; n=5$ brains), whereas $25 \mathrm{~mm}$ tubocurarine completely abolished fast trill frequencies (Fig. $5 E ; n=5$ brains). Thus, local blockade of nAChRs in n.IX-X eliminates vocal motor production. Statistical analyses of nerve recordings revealed that, compared with saline injection, a high dose of tubocurarine significantly reduced the power relative to the preinjection control peak frequencies (Fig. 5I; saline: $0.56 \pm 0.24 \mu \mathrm{V}^{2} \mathrm{~Hz}^{-1}$; $5 \mathrm{~mm}: 0.088 \pm 0.031 \mu \mathrm{V}^{2}$ $\mathrm{Hz}^{-1}$; $25 \mathrm{~mm}: 0.0014 \pm 0.0004 \mu \mathrm{V}^{2} \mathrm{~Hz}^{-1} ; H=12.51, p=$ 0.0012 ). In addition to qualitative differences in nerve activity, 5 mM tubocurarine injections significantly decreased the peak nerve frequencies compared with saline injections (Fig. 5J; saline: $-0.81 \pm 1.21 \mathrm{~Hz} ; 5 \mathrm{~mm}:-9.28 \pm 2.49 \mathrm{~Hz} ; U=2.5, p=0.0216$ ). Following $25 \mathrm{~mm}$ tubocurarine injections, there was no discernable peak in the fast trill frequency range (Fig. $5 E$ ), so these data were not included in the analysis of the change in peak frequency.

Changes in LFP power spectra mirrored those of nerve spectra. Saline injection had no obvious effect on LFP frequencies (Fig. $5 F ; n=6$ brains), $5 \mathrm{~mm}$ tubocurarine injections caused a shift to a lower band of frequencies (Fig. $5 G ; n=4$ brains), and 25 mu tubocurarine eliminated all fast trill frequencies (Fig. $5 \mathrm{H} ; n=$ 4 brains). The relative power at the peak LFP frequency was significantly lower following the $25 \mathrm{~mm}$ tubocurarine injections (Fig. $5 \mathrm{~K}$; saline: $0.61 \pm 0.10 \mu \mathrm{V}^{2} \mathrm{~Hz}^{-1} ; 5 \mathrm{~mm}$ : $0.14 \pm 0.049 \mu \mathrm{V}^{2}$ $\mathrm{Hz}^{-1} ; 25 \mathrm{~mm}: 0.011 \pm 0.0075 \mu \mathrm{V}^{2} \mathrm{~Hz}^{-1} ; H=11.02, p=$ $0.0035)$. As with nerve recordings, there was a significant decrease in peak frequency relative to control following $25 \mathrm{~mm}$ tubocurarine injection (Fig. $5 \mathrm{~L}$; saline: $0.00 \pm 1.78 \mathrm{~Hz} ; 5 \mathrm{~mm}:-8.55 \pm 1.22$ $\mathrm{Hz} ; U=0, p=0.0048)$. Together, these results show local block- 
A
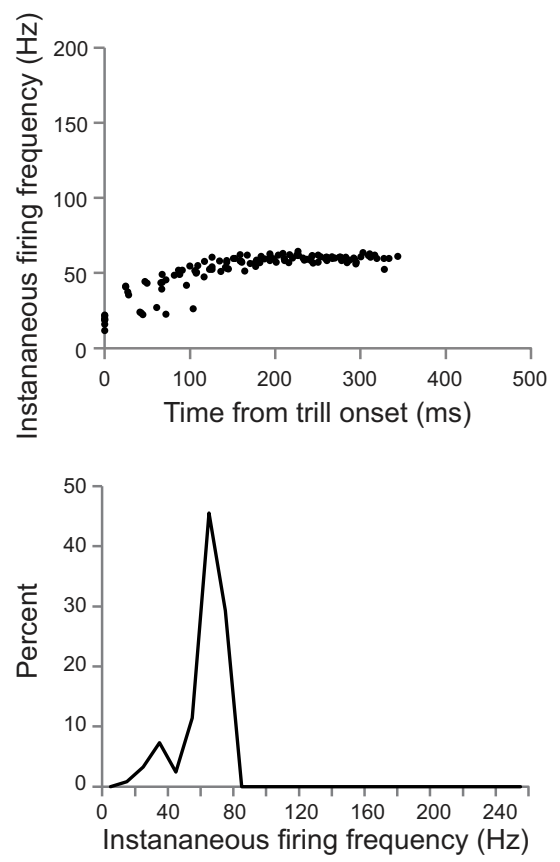

D
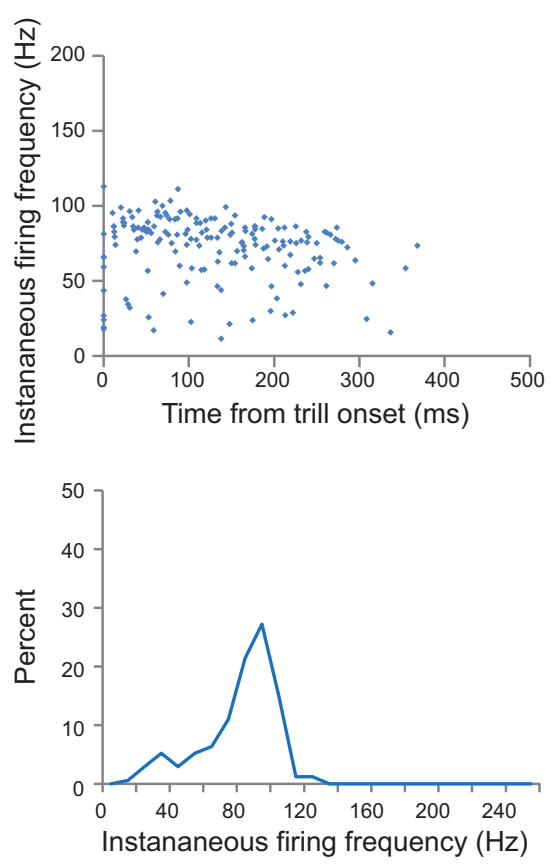

B
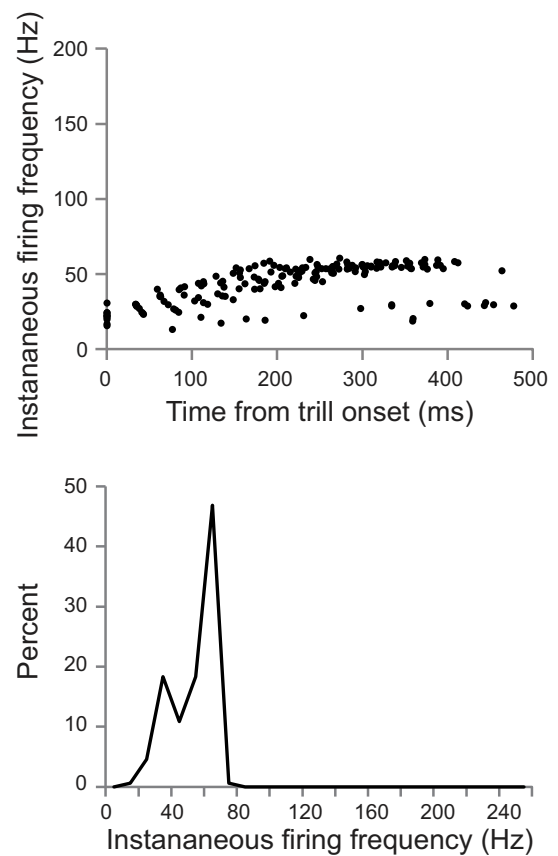

E
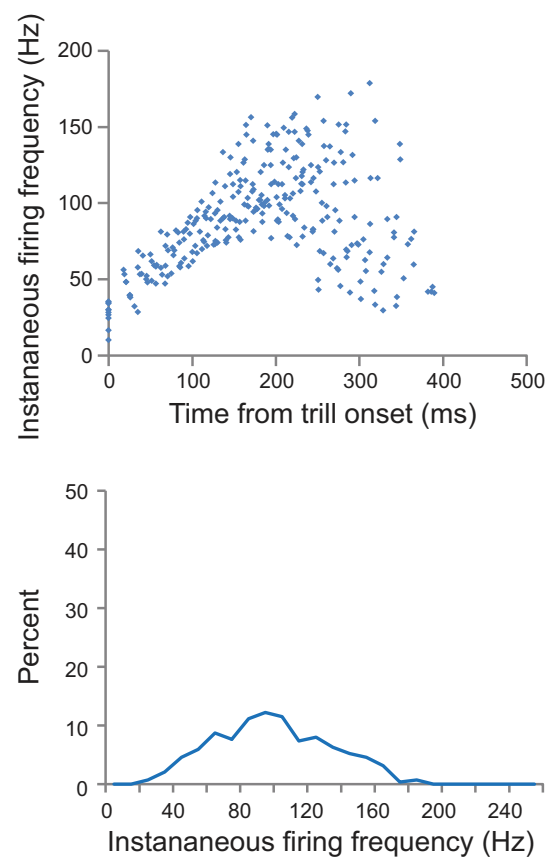

C
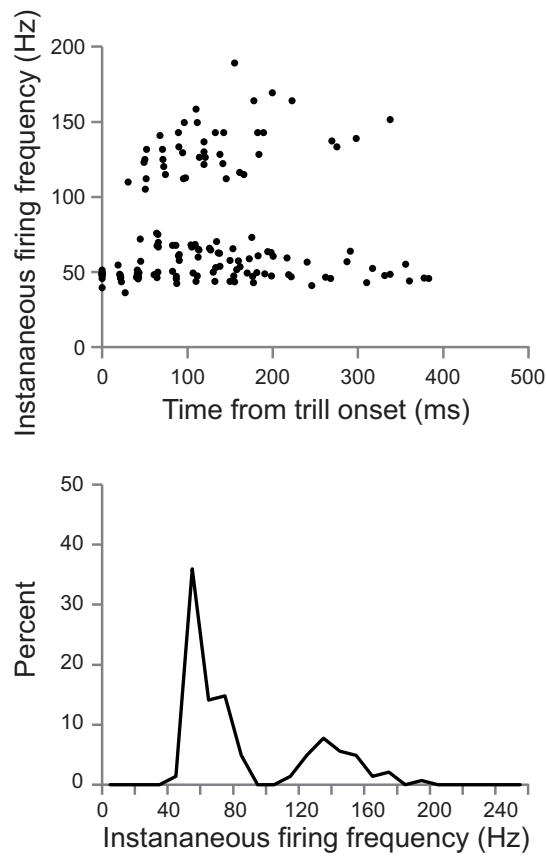

$\mathbf{F}$
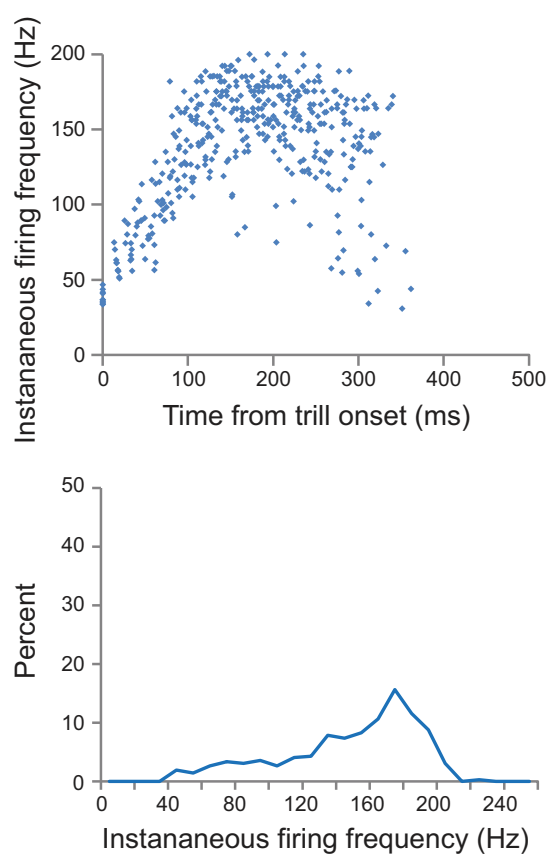

Figure 3. Spike rate variability within and across individual premotor neurons in intact versus transected brains. $\boldsymbol{A}-\boldsymbol{C}$, Scatterplots of spike frequency versus time for three individual premotor FTNs in intact control brains (top) with corresponding spike rate histograms (bottom). Spike rates increase at the beginning of each trill, with the majority of spikes occurring in the fast trill range of $50-60 \mathrm{~Hz}$. Some cells (as in C) also exhibit a higher band of spike rates due to doublet or triplet spikes occurring with some nerve CAPs. Other cells have sporadic low spike rates due to spike failures (as in $\boldsymbol{B}$ ). Corresponding spike rate histograms show a major narrow peak in the range of fast trill rates. $\boldsymbol{D}-\boldsymbol{F}$, Scatterplots of spike frequency versus time for three individual premotor FTNs recorded in transected brains (top) with corresponding spike rate histograms (bottom). The majority of FTN spikes in transected brains are produced at rates much faster than the normal range. Some cells maintain a fairly narrow band of spike frequencies (as in $\boldsymbol{D}$ ), albeit at higher than normal rates; other cells initially spike near fast trill rates but then accelerate to faster and broader frequency bands $(\boldsymbol{E}, \boldsymbol{F})$. Corresponding spike rate histograms show peaks that are faster and broader than those seen in recordings from intact brains.

ade of nAChRs in n.IX-X eliminates both laryngeal nerve output and premotor rhythm generation.

\section{Motor-to-premotor pathway: nerve stimulations}

Tubocurarine injections into n.IX-X (Fig. 5) had a similar effect on premotor activity as brain transections (between n.IX-X and
DTAM; Fig. 2) and motor neuron silencing (Fig. 4), supporting the hypothesis that the motor-to-premotor feedback interneurons may be activated by cholinergic motor neuron inputs. If this hypothesis is correct, then there must be an indirect connection (at least two synapses) between n.IX-X motor neurons and premotor neurons in DTAM. To test this prediction, we stimulated 
A

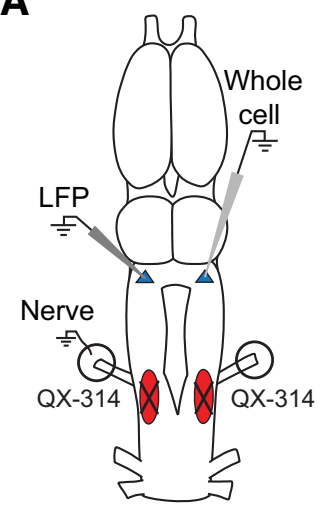

B
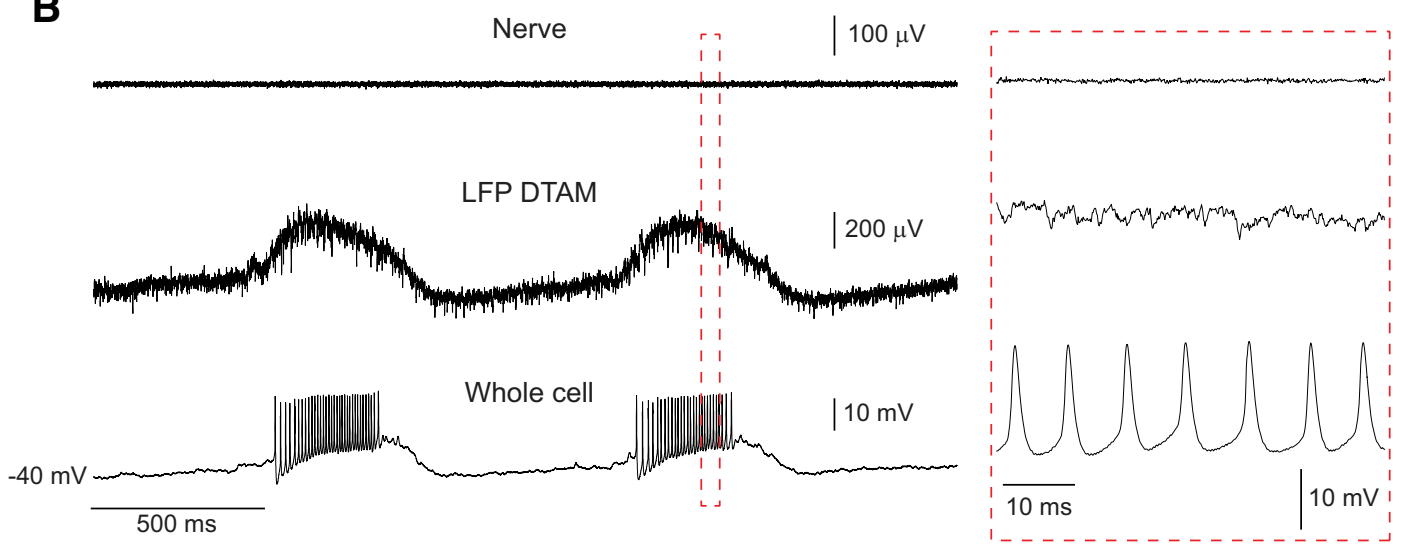

C

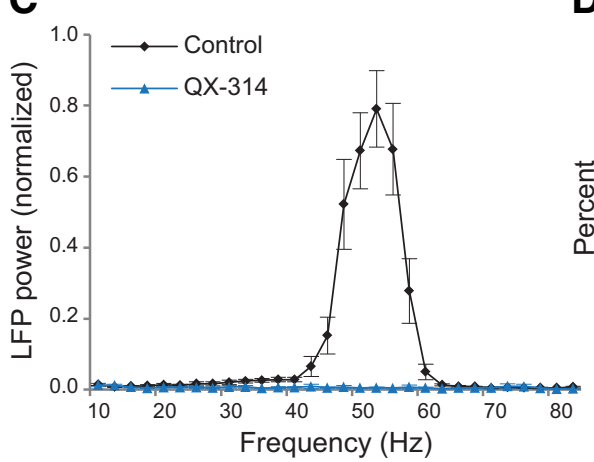

D

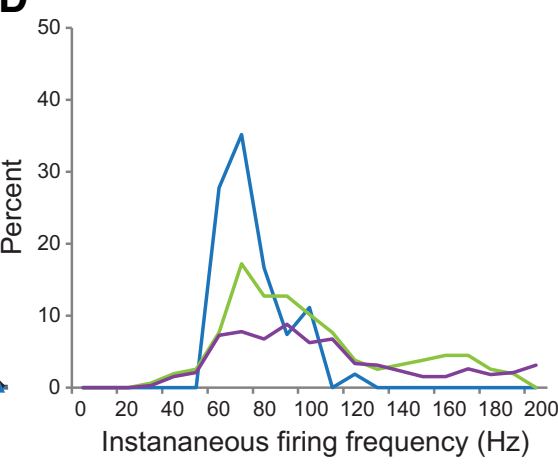

E

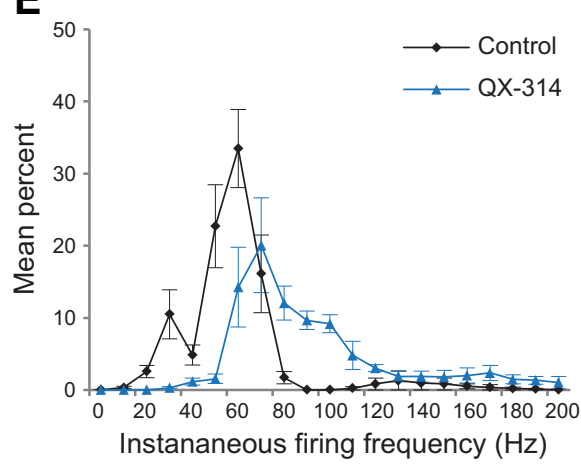

Figure 4. Silencing motor neurons disrupts premotor rhythms. $A$, Laryngeal nerve activity was silenced with the intracellular $\mathrm{Na}^{+}$channel blocker $Q X-314$ before recording from premotor neurons in DTAM. Circles around nerves represent Vaseline wells that were filled with the drug. $\boldsymbol{B}$, Nerve activity is silenced by QX-314 (top), but 5 -HT continues to induce activity in DTAM; LFP waves (middle) and long-lasting depolarizations in FTNs (bottom) persist; however, these lack the normal fast trill rhythms present in control brains. Red box represents area of expanded traces. C, Power spectra of LFP: predrug $50-60 \mathrm{~Hz}$ rhythms are lost following motor neuron silencing by QX-314 ( $n=5$ brains). Values are mean \pm SEM. D, Spike rate histograms for three FTNs show that spike rates are faster and more variable in QX-314-treated brains ( $10 \mathrm{~Hz}$ bins; $n=3$ cells from separate brains). E, Mean FTN spike rate distributions for all control and QX-314 FTNs ( $n=6$ and $n=3$ cells, respectively, from separate brains; no statistical tests were performed due to small sample size). Control FTNs same as in Figure 2F. Values are mean \pm SEM.

N.IX-X while recording individual FTNs (Fig. 6A); 12 of 15 FTNs showed an observable response to stimulations, with most of these displaying a relatively short latency IPSP (11 of 12 cases), with onset times ranging from 7.8 to $20.8 \mathrm{~ms}$ (Fig. $6 B, C$; $12.9 \pm$ $1.15 \mathrm{~ms})$. The average PSP amplitude varied between $-1.1 \mathrm{mV}$ and $-8.0 \mathrm{mV}$ (Fig. $6 D$; mean \pm SEM: $3.52 \pm 0.63 \mathrm{mV}$ ). In 1 case, we instead observed a relatively short latency $(22 \mathrm{~ms})$ EPSP with an average amplitude of $6.6 \mathrm{mV}$ (data not shown). The onset of IPSPs elicited by contralateral stimulations was significantly delayed $(15.7 \pm 1.6 \mathrm{~ms}, n=5$ cells in 5 brains) compared with those elicited by ipsilateral stimulations $(10.5 \pm 0.9 \mathrm{~ms} ; n=6$ cells in 6 brains; $U=3, p=0.0303, n=5$ cells in 5 brains; Fig. $6 C$ ). The amplitude of IPSPs induced by contralateral stimulations $(-3.8 \pm 1.0 \mathrm{mV})$ were not significantly different from those arising from ipsilateral stimulations $(-3.3 \pm 0.8 \mathrm{mV} ; U=11.5$, $p=0.5714$; Fig. 6D).

Results of tubocurarine injections into n.IX-X support the prediction that the putative link between motor neurons and DTAM premotor neurons involves nAChRs. To test this, we bath-applied tubocurarine $(25 \mu \mathrm{M})$ during nerve stimulation to block putative motor neuron inputs onto feedback projection interneurons. Drug application rapidly and reversibly blocked PSPs in 5 of 5 cells (from 5 separate brains) (Fig. 6E, F; Friedman test, $p=0.0133$ ). Together, these results reveal the existence of a connection between n.IX-X motor neurons and premotor vocal neurons, supporting the notion that motor neuron activity tunes rhythmic premotor activity.

\section{Discussion}

The goal of this study was to identify the function of an ascending motor-to-premotor projection in the X. laevis vocal CPG. Our results indicate that this projection provides a feedback signal that tunes and synchronizes the activity of FTNs in the premotor nucleus, DTAM. This feedback signal is activated by motor neurons via cholinergic input onto interneurons that project to DTAM. Thus, vocal CPG function is regulated by motor neurons.

\section{Motor nucleus feedback tunes and synchronizes premotor spiking}

Our results provide strong evidence that the feedback projection tunes premotor activity underlying fast trill production. In transected brains, FTNs depolarize and spike during LFP waves, but spike rates were faster than in intact brains. LFP power spectra in transected brains revealed a complete loss of the $50-60 \mathrm{~Hz}$ phasic activity, indicating the loss of synchronous premotor spiking. Therefore, the feedback projection appears to serve two functions: it slows FTN spiking and promotes spike synchrony.

\section{Vocal rhythms and premotor synchrony require motor neuron input}

Back-filling laryngeal nerve axons with an intracellular sodium channel blocker, QX-314, recapitulated the effect of transections; 5-HT induced DTAM LFP waves that lacked the fast trill rhythms, and FTNs produced spikes at faster and broader rates than in con- 
A
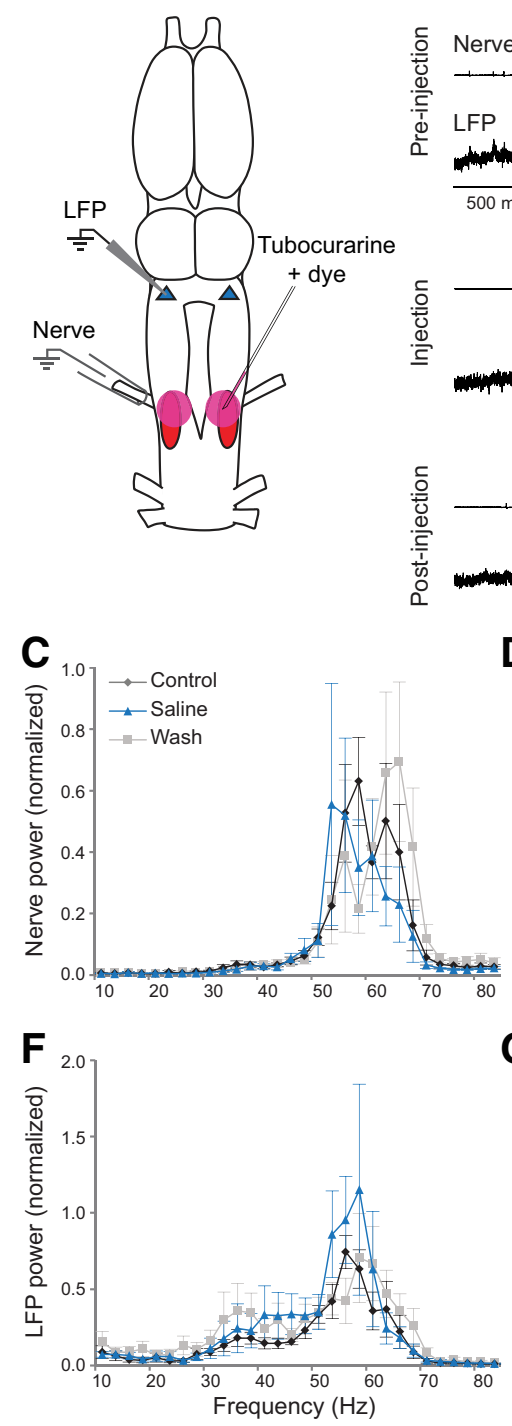

B Saline

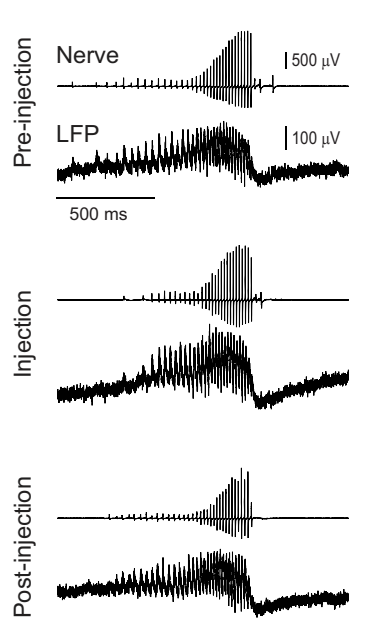

D

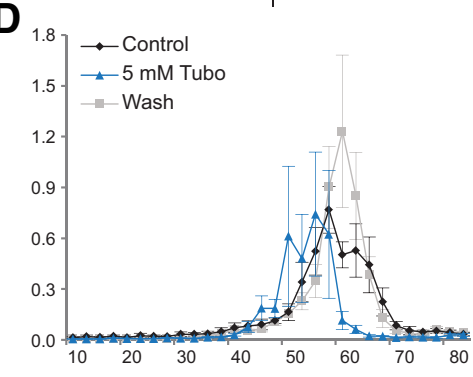

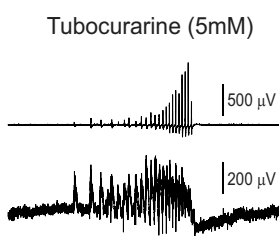

Tubocurarine $(25 \mathrm{mM})$
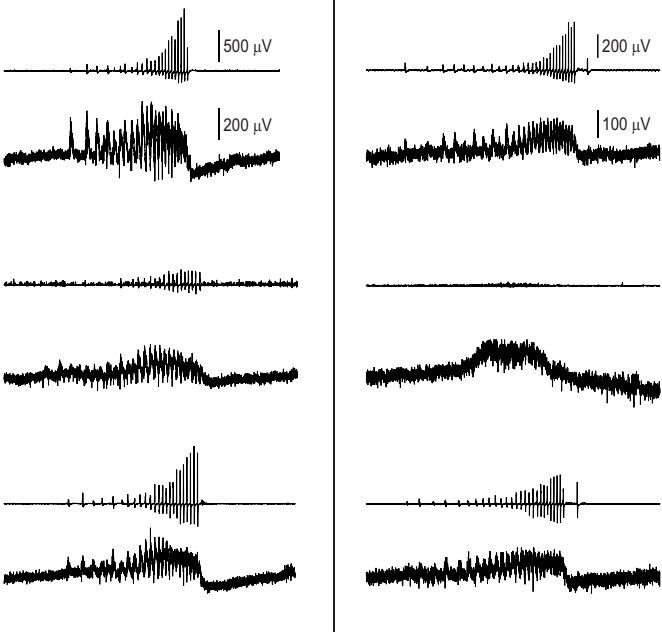

$\mathbf{E}$
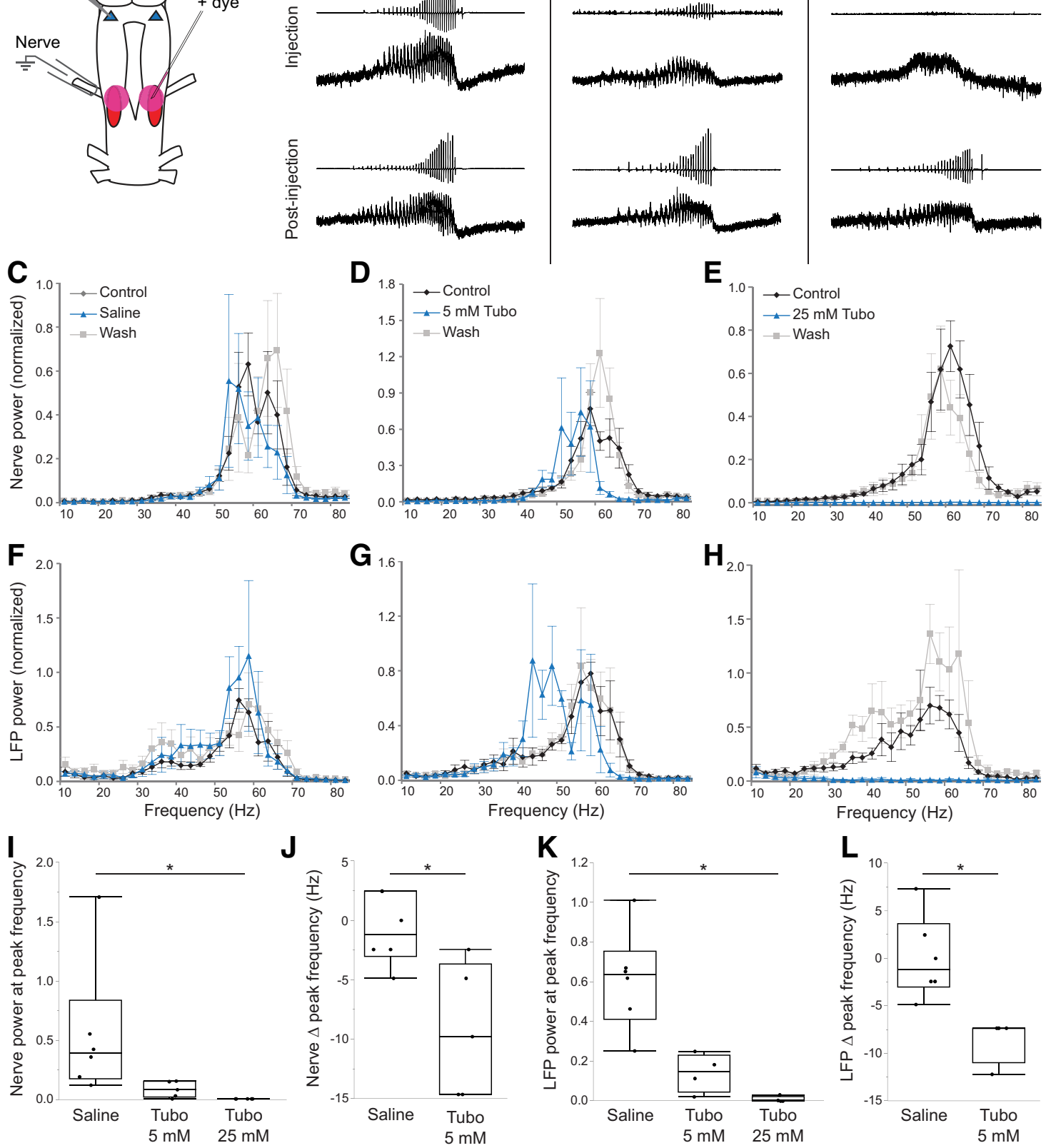

Figure 5. Blocking $\mathrm{nAChRs}$ in the motor nucleus disrupts premotor activity. $A$, The $\mathrm{nAChR}$ blocker tubocurarine or saline was pressure injected bilaterally into $\mathrm{n}$. IX-X while recording the laryngeal nerve and DTAM LFP. Pink circles represent injection site. B, Simultaneous nerve and LFP recordings for saline controls, $5 \mathrm{~mm}$ tubocurarine, and $25 \mathrm{~mm}$ tubocurarine preinjection (top), immediately following injection (middle), and after washout (bottom). Saline controls produced normal fictive song and DTAM activity, but tubocurarine disrupted (PG function in a dose-dependent manner. $\boldsymbol{C}-\boldsymbol{E}$, Power spectra of nerve recordings for saline $(\boldsymbol{C}), 5 \mathrm{~mm}$ tubocurarine (Tubo) $(\boldsymbol{D})$, and $25 \mathrm{~mm}$ tubocurarine $(\boldsymbol{E})$ injections $(n=6, n=5$, and $n=5$ brains, respectively). $\boldsymbol{F}-\boldsymbol{H}$, Power spectrum of LFP for saline $(\boldsymbol{F}), 5 \mathrm{~mm}$ tubocurarine $(\boldsymbol{G})$, and $25 \mathrm{~mm}$ tubocurarine $(\boldsymbol{H})$ injections $(n=6, n=4$, and $n=4$ brains, respectively). Values are mean \pm SEM for all graphs. $I$, Effect of tubocurarine injections on nerve power at control peak frequencies relative to saline controls $\left(n=6, n=5\right.$, and $n=5$ brains, respectively). ${ }^{*} p=0.0012$. $\boldsymbol{J}$, Nerve power spectra show a decrease in peak frequency after $5 \mathrm{~mm}$ tubocurarine injection compared with saline controls $(n=5$ and $n=6$ brains, respectively). $K$, Effect of tubocurarine injections on LFP power at control peak frequencies relative to saline controls $\left(n=6, n=4\right.$, and $n=4$ brains, respectively). ${ }^{*} p=0.0035$. L, LFP power spectra show a decrease in peak frequency after $5 \mathrm{~mm}$ tubocurarine injections compared with saline controls ( $n=4$ and $n=6$ brains, respectively). ${ }^{*} p=0.0048$. Each box plot represents individual data points, median, minimum, maximum, and interquartile range. 
trols. Because studies have shown that QX314 does not cross gap junctions (MannMetzer and Yarom, 1999; Curti and Pereda, 2004), the treatment is most likely due to silencing of motor neurons themselves, not indirectly silencing electrically coupled interneurons. We therefore hypothesized that axon collaterals from motor neurons activate interneurons that project to DTAM.

In support of this hypothesis, injecting a $\mathrm{nAChR}$ antagonist into anteromedial n.IX-X (where motor-to-premotor projection neurons are found) (Zornik and Kelley, 2007) also disrupted premotor rhythms, as determined by a loss of phasic activity in LFP waves. Also in support of our hypothesis, we identified a relatively short-latency (7.8-20.8 ms), primarily inhibitory, input to FTNs that was activated by laryngeal nerve stimulation and required nicotinic signaling. Together, we provide multiple lines of evidence supporting the hypothesis that motor neurons may indirectly modulate premotor neuron firing.

One caveat to the interpretation above is that the laryngeal nerve innervates two distinct muscles: the laryngeal dilators and the glottal muscles (located in the anterior larynx) (Zornik and Kelley, 2007). Thus, it is possible that inhibitory inputs to FTNs following nerve stimulation arise from glottal motor neuron activation. This scenario is unlikely, however, given the results of motor neuron silencing. Because we know that glottal motor neurons are not active during vocalization (Rhodes et al., 2007; Zornik and Kelley, 2008), it is implausible that inactivation of glottal motor neurons would affect the vocal CPG. We conclude the most likely scenario is that laryngeal motor neurons activate feedback neurons that ultimately inhibit premotor FTNs.

\section{Proposed model for feedback- dependent premotor rhythm generation}

We propose a motor neuron-dependent model of the X. laevis vocal CPG (Fig. 7A). Because DTAM neurons monosynaptically activate motor neurons (Zornik and Kelley, 2008), and FTNs project to n.IX-X, we predict FTNs directly activate laryngeal motor neurons, which induce laryngeal muscle contraction and sound pulses. At the same time, axon collaterals from motor neurons provide an excitatory, cholinergic signal onto n.IX-X interneurons. These neurons ultimately provide inhibitory feedback inputs to FTNs (directly or via intervening inhibitory interneurons). This model is supported by
A

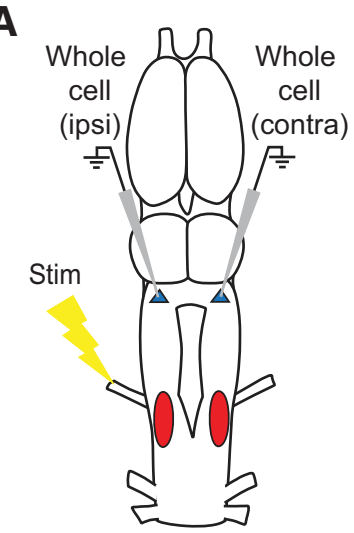

B

C

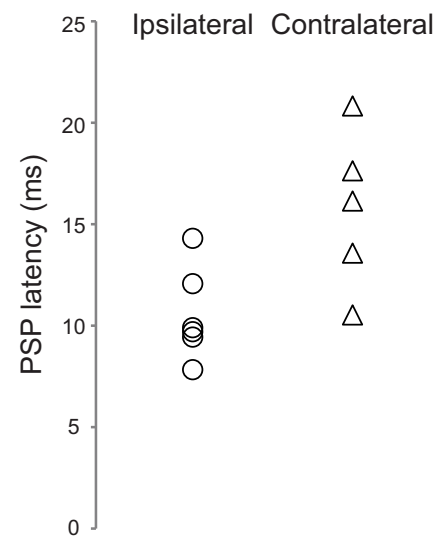

E

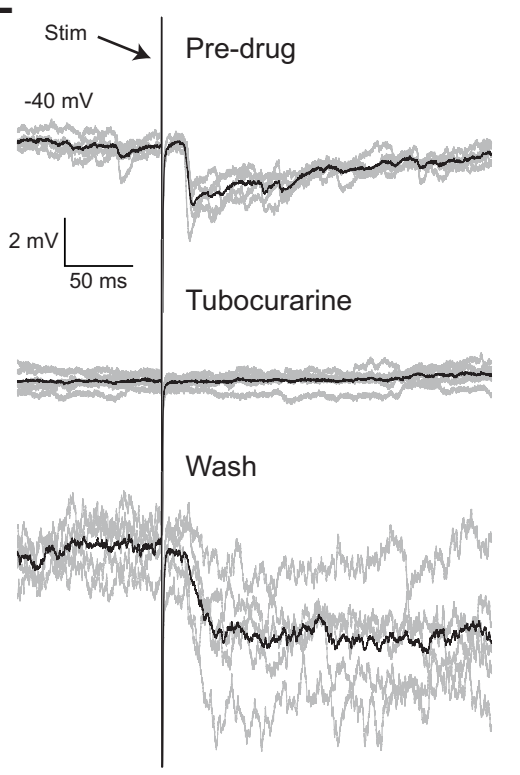

$\mathbf{F}$

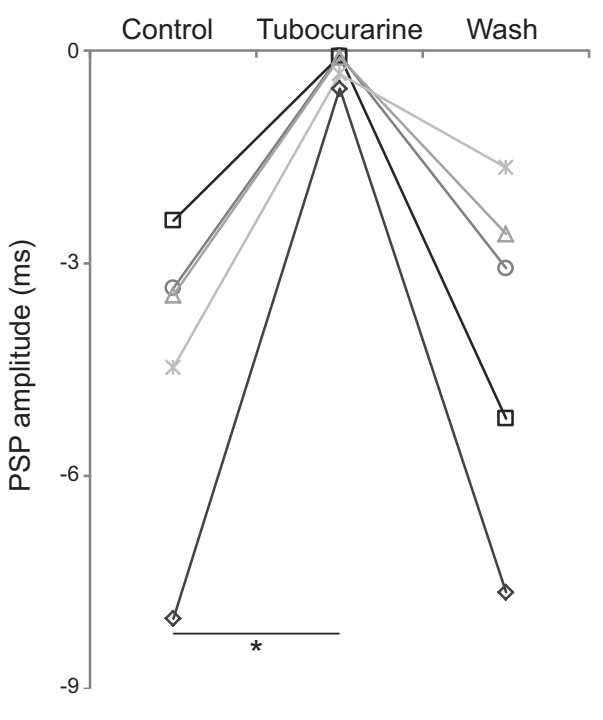

Figure 6. Nerve stimulation induces postsynaptic potentials in premotor FTNs. $\boldsymbol{A}$, The laryngeal nerve was electrically stimulated while recording individual premotor neurons in DTAM. $\boldsymbol{B}$, Example of a nerve stimulation-induced IPSP in a premotor FTN, with 5 example sweeps (gray) and an averaged trace (black). C, Onset latency of IPSPs elicited in FTNs was short latency in ipsilateral and contralateral DTAM (relative to the nerve stimulation electrode; $n=6$ and $n=5$ cells in separate brains; $p=0.03$ ). Each data point indicates the value from a single FTN. $\boldsymbol{D}$, IPSP amplitudes elicited in FTNs were similar in ipsilateral and contralateral DTAM $(p=0.57)$. $\boldsymbol{E}$, Example traces of nerve stimulations combined with application of the nAChR blocker tubocurarine: no PSPs are observed following application of the drug, but PSPs return following washout. $\boldsymbol{F}$, Application of the $\mathrm{nAChR}$ blocker tubocurarine completely and reversibly blocks the PSP in all cases, with near-normal return to baseline amplitude after washout $(n=5$ cells from separate brains; $p=0.013)$. 
A

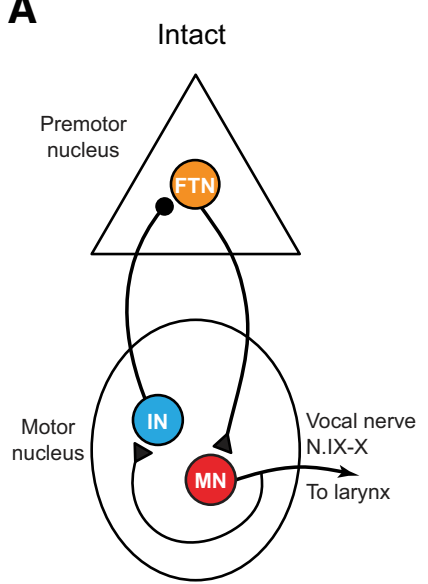

B

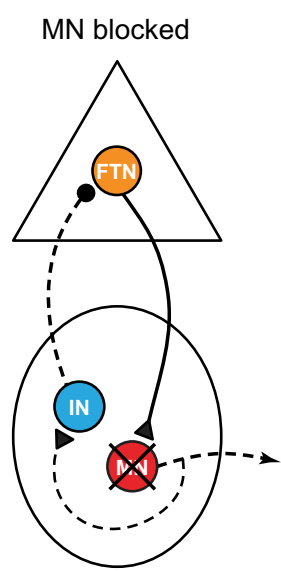

C

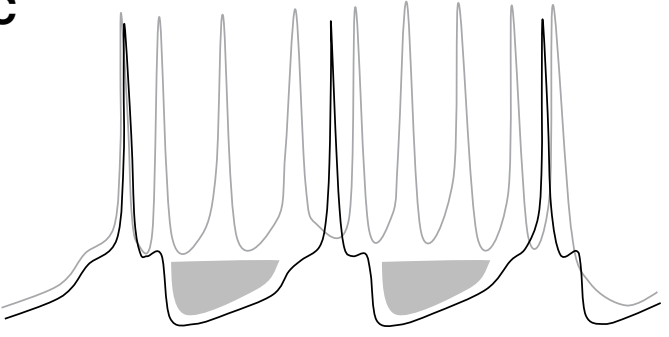

D
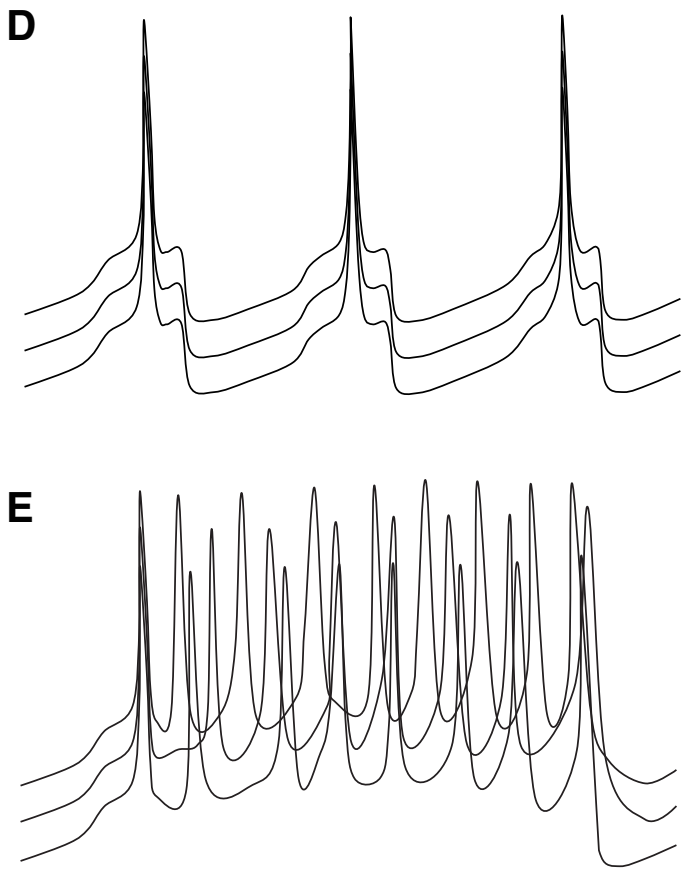

Figure 7. An updated model of the vocal CPG. $A$, Our results support the hypothesis that motor neuron collaterals form a cholinergic synapse onto interneurons in the motor nucleus that project to the premotor nucleus. These are likely inhibitory neurons and are hypothesized to synapse directly onto FTNs in DTAM. B, According to our model, inactivating motor neurons eliminates the feedback inhibition pathway (indicated by dashed lines). C, Hypothetical membrane potentials of FTNs in which the feedback signal is intact (black line) or disrupted (gray line). In the intact circuit, FTN spikes are following by IPSPs (shaded area). In the absence of the feedback signal (via transection, motor neuron silencing, or cholinergic antagonist), IPSPs no longer follow spikes, inducing increased firing rates. D, Hypothetical membrane potentials of three FTNs in an intact brain. In this scenario, spike synchrony is ensured by motor neuron-dependent IPSPS, leading to entrained patterns of postinhibitory rebound. $\boldsymbol{E}$, Membrane potentials of three hypothetical FTNs in which feedback inhibition is eliminated. When FTNs no longer receive simultaneous IPSPs, spikes are no longer entrained, and each cell generates a faster spike train without temporal coordination between neurons.

current and previous findings that FTNs receive inhibitory inputs shortly after each nerve CAP (Fig. 2B) (Zornik and Yamaguchi, 2012). When the feedback signal is eliminated (via transection or motor neuron silencing), IPSPs are no longer apparent (Figs. 2D, $7 C$ ), leading to an increased spike rate. Therefore, FTN synchrony is maintained in the intact circuit through cycle-by-cycle inhibition allowing synchronous firing upon postinhibitory rebound (Fig. 7D); in the absence of this entraining signal, FTN spikes become faster and desynchronized (Fig. $7 E$ ).

While our model requires rapid ( $\sim 5 \mathrm{~ms}$ ) feedback inhibition, the nerve stimulation-induced IPSPs observed in FTNs ranged from $\sim 7$ to $20 \mathrm{~ms}$. A possible explanation for this discrepancy is that feedback interneurons are likely in a hyperpolarized state during nerve stimulation experiments (when the vocal CPG is inactive). Although nerve stimulation is able to induce a spike in the feedback interneuron in these experiments, the spike onset time of these neurons is likely to be much longer than it would be in the active circuit. In the activated neurons, the synaptic delay is likely shorter due to depolarization (bringing the cell closer to spike threshold), and possibly due to a decrease in time constant of the membrane (caused by the opening of voltagegated channels). An alternative possibility is that the motor neuron-dependent feedback inhibition leads to a slow, tonic inhibition that prevents excessive depolarization of FTNs, thus favoring the production of spikes at fast trill rates. Given that phasic IPSPs are eliminated by disrupting the feedback signal, however, we believe the hypothesis that motor neurons drive cycleby-cycle feedback inhibition is the most likely mechanism for tuning FTN firing rate.

We measured nerve stimulation-induced IPSPs in FTNs both ipsilateral and contralateral to the stimulated nerve. IPSP amplitudes did not vary between ipsilateral and contralateral inputs, suggesting a potential role for the feedback pathway in maintaining bilateral synchrony of motor output, a requirement for sound production (Yager, 1992). We did find a difference in IPSP latency, however, with IPSP latency in ipsilateral FTNs being shorter than to contralateral FTNs. As discussed above, it is possible that feedback latency in the active CPG is much shorter, and the actual difference in latencies between ipsilateral and contralateral feedback signals may be negligible during CPG production of fast trill. Future characterization of the synaptic delay between motor neurons and feedback interneurons will be required to resolve this question.

\section{Role of motor neurons in vertebrate motor circuits}

Invertebrate CPGs have been studied in detail in a range of species, including crustaceans (Marder and Bucher, 2007), mollusks (Wentzell et al., 2009), and leech (Kristan et al., 2005; Friesen and Kristan, 2007). In some cases, motor neurons participate in the rhythm generating circuit (Marder and Bucher, 2007). In vertebrates, there is far less evidence of motor neuron involvement in CPG function. Although connections between motor neurons, both via chemical and electrical synapses, are known to promote network synchrony (Perrins and Roberts, 1995b; Zhang et al., 2009; Chagnaud et al., 2012), there is sparse evidence that motor neurons are playing an active role in regulating CPG activity.

One cell type known to receive input from motor neurons is mammalian Renshaw cells, which form a recurrent feedback loop with motor neurons (Bhumbra et al., 2014). Other evidence for motor neuron feedback in mammals comes from embryonic and neonatal rodent spinal cord studies. In embryonic mouse spinal cord, anatomical evidence revealed motor neuron projections to interneuron-containing regions, and motor neurons appeared capable of initiating spontaneous rhythmic bursting, mediated by excitatory glycinergic and GABAergic interneurons (Hanson and Landmesser, 2003). In mice and rats, stimulating ventral locomotor nerve roots in the disinhibited spinal cord elicits locomotor-like bursting (Machacek and Hochman, 2006; Bonnot et al., 2009; 
O'Donovan et al., 2010), suggesting the presence of motor neuron collaterals onto interneurons other than Renshaw cells. In the Xenopus tadpole swimming CPG, blocking presumptive motor neuron synapses disrupts normal rhythms in premotor interneurons (Perrins and Roberts, 1995a). In the chick, putative avian Renshaw cell homologs, R-interneurons, appear capable of inducing locomotor circuit activity; spontaneous bouts of activity seem to be driven or enhanced by motor neurons, as blocking cholinergic receptors reduces this phenomenon (Wenner and O'Donovan, 1999, 2001). These results indicate that, at least during embryonic stages, Rinterneurons project to CPG neurons in the locomotor circuit (activation is likely due to the fact that R-interneurons are excitatory during embryonic development). If these projections persist in adulthood, it would provide a pathway for motor neurons to influence CPG function, albeit via inhibition, as R-interneurons are inhibitory in adults.

Because the above studies were performed in embryonic and neonatal animals, it is not clear whether these connections via chemical synapses persist in adult vertebrate spinal circuits. However, recent work in the juvenile and adult zebrafish swimming CPG showed that motor neurons can influence premotor activity via gap junctions rather than chemical transmission (Song et al., 2016). This finding provides an example of motor neuron involvement later in development and extends the number of studies indicating an active role for motor neurons in locomotor CPGs.

To our knowledge, the findings in this study represent the first evidence that motor neurons can regulate a hindbrain CPG. This raises the intriguing possibility that motor neuron involvement in CPG function is more common than generally assumed and therefore warrants examination in other nonspinal CPGs. Such investigations may find that canonical top-down models of vertebrate motor circuits, in which motor neurons act as relays between CPG neurons and muscles, are incomplete. Instead, vertebrate circuits may more closely resemble invertebrate CPGs, with motor neurons serving as critical components of CPGs.

\section{References}

Arshavsky YI, Deliagina TG, Orlovsky GN (1997) Pattern generation. Curr Opin Neurobiol 7:781-789. CrossRef Medline

Bhumbra GS, Bannatyne XB, Watanabe M, Todd AJ, Maxwell DJ, Beato M (2014) The recurrent case for the Renshaw cell. J Neurosci 34:1291912932. CrossRef Medline

Bonnot A, Chub N, Pujala A, O’Donovan MJ (2009) Excitatory actions of ventral root stimulation during network activity generated by the disinhibited neonatal mouse spinal cord. J Neurophysiol 101:2995-3011. CrossRef Medline

Chagnaud BP, Zee MC, Baker R, Bass AH (2012) Innovations in motoneuron synchrony drive rapid temporal modulations in vertebrate acoustic signaling. J Neurophysiol 107:3528-3542. CrossRef Medline

Curti S, Pereda AE (2004) Voltage-dependent enhancement of electrical coupling by a subthreshold sodium current. J Neurosci 24:3999-4010. CrossRef Medline

Friesen WO, Kristan WB (2007) Leech locomotion: swimming, crawling, and decisions. Curr Opin Neurobiol 17:704-711. CrossRef Medline

García-Crescioni K, Miller MW (2011) Revisiting the reticulum: feedforward and feedback contributions to motor program parameters in the crab cardiac ganglion microcircuit. J Neurophysiol 106:2065-2077. CrossRef Medline

GrillnerS (2006) Biological pattern generation: the cellular and computational logic of networks in motion. Neuron 52:751-766. CrossRef Medline

Guertin PA, Steuer I (2009) Key central pattern generators of the spinal cord. J Neurosci Res 87:2399-2405. CrossRef Medline

Hanson MG, Landmesser LT (2003) Characterization of the circuits that generate spontaneous episodes of activity in the early embryonic mouse spinal cord. J Neurosci 23:587-600. Medline

Kiehn O (2006) Locomotor circuits in the mammalian spinal cord. Annu Rev Neurosci 29:279-306. CrossRef Medline
Kiehn O (2011) Development and functional organization of spinal locomotor circuits. Curr Opin Neurobiol 21:100-109. CrossRef Medline

Kiehn O, Butt SJ (2003) Physiological, anatomical and genetic identification of CPG neurons in the developing mammalian spinal cord. Prog Neurobiol 70:347-361. CrossRef Medline

Kristan WB Jr, Calabrese RL, Friesen WO (2005) Neuronal control of leech behavior. Prog Neurobiol 76:279-327. CrossRef Medline

Machacek DW, Hochman S (2006) Noradrenaline unmasks novel selfreinforcing motor circuits within the mammalian spinal cord. J Neurosci 26:5920-5928. CrossRef Medline

Mann-Metzer P, Yarom Y (1999) Electrotonic coupling interacts with intrinsic properties to generate synchronized activity in cerebellar networks of inhibitory interneurons. J Neurosci 19:3298-3306. Medline

Marder E, Bucher D (2001) Central pattern generators and the control of rhythmic movements. Curr Biol 11:R986-R996. CrossRef Medline

Marder E, Bucher D (2007) Understanding circuit dynamics using the stomatogastric nervous system of lobsters and crabs. Annu Rev Physiol 69: 291-316. CrossRef Medline

Mentis GZ, Alvarez FJ, Bonnot A, Richards DS, Gonzalez-Forero D, Zerda R, O’Donovan MJ (2005) Noncholinergic excitatory actions of motoneurons in the neonatal mammalian spinal cord. Proc Natl Acad Sci U S A 102:7344-7349. CrossRef Medline

Nishimaru H, Restrepo CE, Ryge J, Yanagawa Y, Kiehn O (2005) Mammalian motor neurons corelease glutamate and acetylcholine at central synapses. Proc Natl Acad Sci U S A 102:5245-5249. CrossRef Medline

Nishimaru H, Restrepo CE, Kiehn O (2006) Activity of Renshaw cells during locomotor-like rhythmic activity in the isolated spinal cord of neonatal mice. J Neurosci 26:5320-5328. CrossRef Medline

O’Donovan MJ, Bonnot A, Mentis GZ, Chub N, Pujala A, Alvarez FJ (2010) Mechanisms of excitation of spinal networks by stimulation of the ventral roots. Ann N Y Acad Sci 1198:63-71. CrossRef Medline

Perrins R, Roberts A (1995a) Cholinergic contribution to excitation in a spinal locomotor central pattern generator in Xenopus embryos. J Neurophysiol 73:1013-1019. Medline

Perrins R, Roberts A (1995b) Cholinergic and electrical synapses between synergistic spinal motoneurones in the Xenopus laevis embryo. J Physiol 485:135-144. CrossRef Medline

Rhodes HJ, Yu HJ, Yamaguchi A (2007) Xenopus vocalizations are controlled by a sexually differentiated hindbrain central pattern generator. J Neurosci 27:1485-1497. CrossRef Medline

Roberts A, Li WC, Soffe SR (2012) A functional scaffold of CNS neurons for the vertebrates: the developing Xenopus laevis spinal cord. Dev Neurobiol 72:575-584. CrossRef Medline

Roberts A, Conte D, Hull M, Merrison-Hort R, al Azad AK, Buhl E, Borisyuk $\mathrm{R}$, Soffe SR (2014) Can simple rules control development of a pioneer vertebrate neuronal network generating behavior? J Neurosci 34:608621. CrossRef Medline

Simpson HB, Tobias ML, Kelley DB (1986) Origin and identification of fibers in the cranial nerve IX-X complex of Xenopus laevis: Lucifer Yellow backfills in vitro. J Comp Neurol 244:430-444. CrossRef Medline

Song J, Ampatzis K, Björnfors ER, El Manira A (2016) Motor neurons control locomotor circuit function retrogradely via gap junctions. Nature 529:1-5. CrossRef Medline

Tobias ML, Kelley DB (1987) Vocalizations by a sexually dimorphic isolated larynx: peripheral constraints on behavioral expression. J Neurosci 7:3191-3197. Medline

Usiak MF, Landmesser LT (1999) Neuromuscular activity blockade induced by muscimol and D-tubocurarine differentially affects the survival of embryonic chick motoneurons. J Neurosci 19:7925-7939. Medline

Wenner P, O'Donovan MJ (1999) Identification of an interneuronal population that mediates recurrent inhibition of motoneurons in the developing chick spinal cord. J Neurosci 19:7557-7567. Medline

Wenner P, O’Donovan MJ (2001) Mechanisms that initiate spontaneous network activity in the developing chick spinal cord. J Neurophysiol 86: 1481-1498. Medline

Wentzell MM, Martínez-Rubio C, Miller MW, Murphy AD (2009) Comparative neurobiology of feeding in the opisthobranch sea slug, Aplysia, and the pulmonate snail, Helisoma: evolutionary considerations. Brain Behav Evol 74:219-230. CrossRef Medline

Wetzel DM, Kelley DB (1983) Androgen and gonadotropin effects on male 
mate calls in South African clawed frogs, Xenopus laevis. Horm Behav 17:388-404. CrossRef Medline

Wetzel DM, Haerter UL, Kelley DB (1985) A proposed neural pathway for vocalization in South African clawed frogs, Xenopus laevis. J Comp Physiol A 157:749-761. CrossRef Medline

Yager DD (1992) A unique sound production mechanism in the pipid anuran Xenopus borealis. Zool J Linn Soc 104:351-375. CrossRef

Yamaguchi A, Kelley DB (2000) Generating sexually differentiated vocal patterns: laryngeal nerve and EMG recordings from vocalizing male and female African clawed frogs (Xenopus laevis). J Neurosci 20:1559-1567. Medline

Zhang HY, Li WC, Heitler WJ, Sillar KT (2009) Electrical coupling synchronises spinal motoneuron activity during swimming in hatchling Xenopus tadpoles. J Physiol 587:4455-4466. CrossRef Medline
Zornik E, Kelley DB (2007) Breathing and calling: neuronal networks in the Xenopus laevis hindbrain. J Comp Neurol 501:303-315. CrossRef Medline

Zornik E, Kelley DB (2008) Regulation of respiratory and vocal motor pools in the isolated brain of Xenopus laevis. J Neurosci 28:612-621. CrossRef Medline

Zornik E, Kelley DB (2011) A neuroendocrine basis for the hierarchical control of frog courtship vocalizations. Front Neuroendocrinol 32:353-366. CrossRef Medline

Zornik E, Yamaguchi A (2012) Coding rate and duration of vocalizations of the frog, Xenopus laevis. J Neurosci 32:12102-12114. CrossRef Medline

Zornik E, Katzen AW, Rhodes HJ, Yamaguchi A (2010) NMDARdependent control of call duration in Xenopus laevis. J Neurophysiol 103: 3501-3515. CrossRef Medline 